Article

\title{
Electrophysical Properties of PMN-PT-Ferrite Ceramic Composites
}

\section{Dariusz Bochenek*D, Przemysław Niemiec, Ryszard Skulski and Dagmara Brzezińska}

Faculty of Science and Technology, Institute of Materials Engineering, University of Silesia in Katowice, 75 Pułku Piechoty 1a, 41-500 Chorzów, Poland; przemyslaw.niemiec@us.edu.pl (P.N.); ryszard.skulski@us.edu.pl (R.S.); dagmara.brzezinska@us.edu.pl (D.B.)

* Correspondence: dariusz.bochenek@us.edu.pl

Received: 19 September 2019; Accepted: 8 October 2019; Published: 9 October 2019

\begin{abstract}
Ferroelectromagnetic composites based on (1-x)PMN-(x)PT (PMN-PT) powder and Ni-Zn ferrite powder were obtained and are described in this work. As a ferroelectric component, we used $(1-x)$ PMN- $(x)$ PT solid solution (with $x=0.25,0.28,0.31,0.34,0.37,0.40$ ), synthesized using the sol-gel method. As a magnetic component, we used nickel-zinc ferrite, obtained using classic ceramic technology. The six compositions of PMN-PT used have rhombohedral symmetry, tetragonal one and mixture of these phases (morphotropic phase area), depending on $x$. The final ceramic composite samples were obtained using the classic methods involving the calcination route and pressureless final sintering (densification). The properties of the obtained ceramic composite samples were investigated, including microstructure SEM (scanning electron microscope), dielectric properties, electromechanical properties, and DC (Direct Current) electrical conductivity. Results showed that the microstructures of the PP-F composite samples characterized by larger grains were better crystallized, compared with the microstructures of the PMN-PT ceramic samples. The magnetic properties do not depend on the ferroelectric component of the composite samples, while the insertion of ferrite into the PMN-PT compound reduces the values of remnant and spontaneous polarization, as well as the coercive field. The dielectric measurements also indicated that the magnetic subsystem influences the dielectric properties. The present results show that the PP-F ceramic composite has good dielectric, magnetic, and piezoelectric properties, which predisposes this type of material to specific applications in microelectronics and micromechatronics.
\end{abstract}

Keywords: PMN-PT solid solutions; Ni-Zn ferrite; ceramic composites; multiferroics; micromechatronics

\section{Introduction}

In recent years, there has been a global search for multiferroics [1-4], magnetoelectric materials [5], materials with coupling between magnetic and polarization orders [6], materials with functional properties [7,8] also in the form of magnetoelectric composites [9-13], lead-free multiferroic composites [14,15], and multiferroic nanocomposites [16,17]. Many methods and techniques for obtaining ceramic powders are known, such as the solid state reaction method, two-stage columbite method [18], sol-gel method [19], coprecipitation method [20], mechanochemical activation [21], selective laser sintering (SLS) [22,23], self-propagating high-temperature synthesis (SHS) [24], gel combustion [25], and others. Each of these methods gives rise to new possibilities; however, at the same time, it requires the use of specific technological conditions and laboratory precision in order to obtain ceramic materials with optimal properties. The sol-gel technology has numerous advantages, e.g., lowers the temperature of the synthesis, provides perfect homogeneity of the powders of the multicomponent compounds, and does not require the use of complicated equipment. The two-phase multiferroic ceramic composites obtained by the authors and described in this paper consist of 
two components-ferroelectric/relaxor and ferromagnetic. As the ferroelectric/relaxor component, $(1-x) \mathrm{PbMg}_{1 / 3} \mathrm{Nb}_{2 / 3} \mathrm{O}_{3}-x \mathrm{PbTiO}_{3}(\mathrm{PMN}-\mathrm{PT})$ was used, while nickel-zinc ferrite $\left(\mathrm{Ni}_{0.64} \mathrm{Zn}_{0.36} \mathrm{Fe}_{2} \mathrm{O}_{4}\right)$ was used as the magnetic component.

$\mathrm{PbMg}_{1 / 3} \mathrm{Nb}_{2 / 3} \mathrm{O}_{3}$ (PMN) is a canonical relaxor with perovskite-type structure [26,27]. The temperature of the maximum dielectric permittivity of $\mathrm{PMN}$ is between $-13^{\circ} \mathrm{C}$ and $-3^{\circ} \mathrm{C}$, depending on the frequency of measurements [28,29]. Of great practical importance are the solid solutions PMN-PT (i.e., $(1-x) \mathrm{PbMg}_{1 / 3} \mathrm{Nb}_{2 / 3} \mathrm{O}_{3}-x \mathrm{PbTiO}_{3}$ (abbreviated in this paper to $\left.\mathrm{PP}\right)$ ). In $(1-x) \mathrm{PMN}-x \mathrm{PT}$, the maximum dielectric permittivity shifts towards higher temperatures with increasing $x$ (from $T_{m}=-3{ }^{\circ} \mathrm{C}$ for $x=0$ to about $T_{m}=227^{\circ} \mathrm{C}$ for $\left.x=0.5[30,31]\right)$. The PMN-PT powders used by us were obtained using the sol-gel method, similar to the method described in Reference [32]. Nickel-zinc ferrite with a general formula $\mathrm{Ni}_{1-x} \mathrm{Zn}_{x} \mathrm{Fe}_{2} \mathrm{O}_{4}$ and spinel-type structure was used as a magnetic component. The composition used by the authors, i.e., $\mathrm{Ni}_{0.64} \mathrm{Zn}_{0.36} \mathrm{Fe}_{2} \mathrm{O}_{4}$, belongs to well-known soft ferrites with a high value of magnetic permeability and relatively high resistance $\rho\left(10^{5} \Omega \mathrm{m}\right)$ [33], and was obtained using the classic ceramic method. The final composite samples were obtained using classic methods with calcination and pressureless final sintering (densification).

In previous work [34], the authors described ceramic composites based on two compositions of $\mathrm{PMN}-\mathrm{PT}$, i.e., $0.72 \mathrm{PbMg}_{1 / 3} \mathrm{Nb}_{2 / 3} \mathrm{O}_{3}-0.28 \mathrm{PbTiO}_{3}$ with rhombohedral symmetry and $0.63 \mathrm{PbMg}_{1 / 3} \mathrm{Nb}_{2 / 3} \mathrm{O}_{3}-0.37 \mathrm{PbTiO}_{3}$ with tetragonal symmetry. For the samples, X-ray Diffraction (XRD) patterns, SEM microstructure, energy dispersive spectrometer (EDS) spectra as well as dielectric, electrical, and magnetic properties were investigated. The obtained results presented in Reference [34] confirmed the existence of ferroelectric and ferrimagnetic properties at room temperature.

In previous work [35], the authors obtained and investigated composites based on six compositions of $(1-x)$ PMN- $x$ PT, with $x=0.25,0.28,0.31,0.34,0.37,0.40$. These compositions of PMN-PT have rhombohedral and tetragonal symmetry, as well as a mixture of these phases (morphotropic phase boundary (MPB)). In the composite samples obtained in such a way, XRD patterns, EDS spectra, as well as dielectric and magnetic properties were investigated [35]. The results confirmed ferroelectric and ferrimagnetic properties at room temperature in the obtained ceramic materials.

In the present work, the authors describe more detailed investigations of the electrophysical and magnetic properties as well as phase transitions of PMN-PT-ferrite ceramic composites with $x=0.25$, $0.28,0.31,0.34,0.37,0.40$ (i.e., the same as in Reference [26]). Inter alia, the following investigations were conducted: SEM microstructure, more detailed dielectric investigations, electromechanical properties, and DC (direct current) electrical conductivity.

\section{Experiment}

In this work, the ceramic samples of the PMN-PT solid solutions and the ceramic samples of the PP-F composites were obtained using the two-step columbite sol-gel technology, and were then compared.

The $(1-x) \mathrm{PbMg}_{1 / 3} \mathrm{Nb}_{2 / 3} \mathrm{O}_{3}-(x) \mathrm{PbTiO}_{3}(\mathrm{PP})$ powders were obtained with the sol-gel technology, using two-step columbite method. In the first step, the $\mathrm{PbMg}_{1 / 3} \mathrm{Nb}_{2 / 3} \mathrm{O}_{3}$ component (PMN) was obtained as a result of the reaction between $\mathrm{Mg}\left(\mathrm{OC}_{2} \mathrm{H}_{5}\right)_{2}$ and $\mathrm{Nb}\left(\mathrm{OC}_{2} \mathrm{H}_{5}\right)_{5}$ in ethyl alcohol, while in the second step, $\mathrm{Pb}\left(\mathrm{CH}_{3} \mathrm{COO}\right)_{2}$ and ethylene glycol were added to the mixture. The $\mathrm{PbTiO}_{3}$ component (PT) was obtained as a result of the reaction between $\mathrm{Pb}\left(\mathrm{CH}_{3} \mathrm{COO}\right)_{2}$ and $\mathrm{Ti}\left(\mathrm{CH}_{3} \mathrm{CH}_{2}-\mathrm{CH}_{2} \mathrm{O}\right)_{4}$. The liquid compositions PMN and PT were mixed together in the proper proportions with $x=0.25,0.28,0.31$, $0.34,0.37,0.40$. After drying the gel to a powder, the sintering (densification) of the PMN-PT samples was conducted by hot uniaxial pressing at the following conduction: $T_{s}=1200{ }^{\circ} \mathrm{C}, t_{s}=2 \mathrm{~h}, p_{s}=10 \mathrm{MPa}$. The technology for obtaining the compositions was described in detail in Reference [22]. The powder of $\mathrm{Ni}_{0.64} \mathrm{Zn}_{0.36} \mathrm{Fe}_{2} \mathrm{O}_{4}$ ferrite was obtained from simple oxides $\mathrm{NiO}$ (Sigma-Aldrich, St. Louis, MO, USA, 99.8\% purity, <50 nm particle size), $\mathrm{Fe}_{2} \mathrm{O}_{3}$ (Sigma-Aldrich $99.98 \%$ purity, $<5 \mu \mathrm{m}$ particle size) and $\mathrm{ZnO}_{2}$ (POCH, Gliwice, Poland, 99.9\% purity, $<45 \mu \mathrm{m}$ particle size), using the calcination technique 
under the conditions of $1100{ }^{\circ} \mathrm{C} / 4 \mathrm{~h}$. The general scheme of the technological process of the PP ceramic samples is presented in Figure 1a.

a)

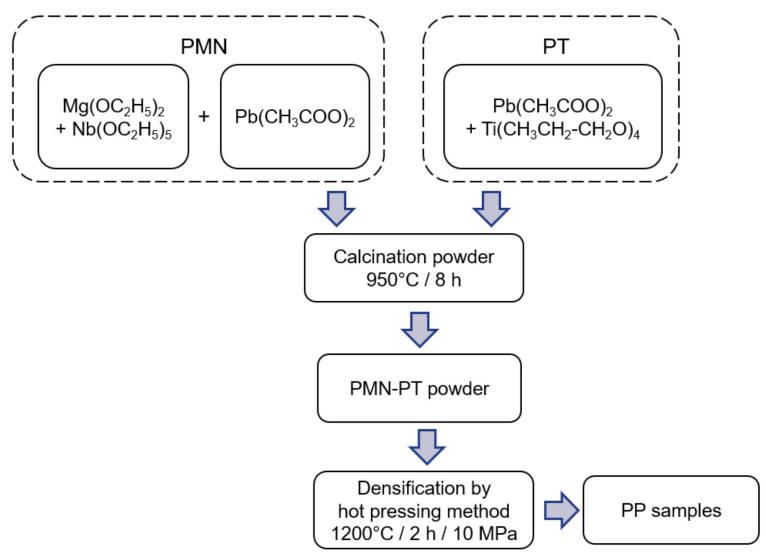

b)

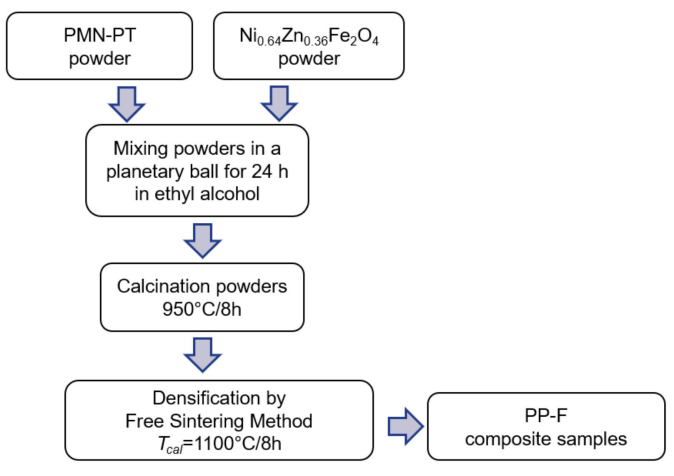

Figure 1. General scheme of technological process: (a) of the (1-x)PMN- $x$ PT (PP) materials, (b) PMN-PT-ferrite (PP-F) composite samples.

The designed composites, based on six compositions of PMN-PT (with $x$ from 0.25 to 0.40 ) and $\mathrm{Ni}_{0.64} \mathrm{Zn}_{0.36} \mathrm{Fe}_{2} \mathrm{O}_{4}$ powder, consisted of $90 \mathrm{wt}-\%$ of PMN-PT type ceramic powder and $10 \mathrm{wt}$ - $\%$ of ferrite powder. The powders of each composition were mixed using a Fritsch planetary ball mill for $15 \mathrm{~h}$ (wet in ethyl alcohol), and the mixture of powders was then calcined in following conditions: $T_{\text {calc }}=950^{\circ} \mathrm{C}$ and $t_{\text {calc }}=8 \mathrm{~h}$. The compacting (densification) of the composite ceramic samples was conducted at a conduction of $T_{s}=1100^{\circ} \mathrm{C}$ by $t_{s}=8 \mathrm{~h}$. Afterwards, the ceramic samples were grinded, polished, and annealed at $700{ }^{\circ} \mathrm{C}$ in order to remove mechanical stresses. The final step of the technological process involved applying the silver paste electrodes onto both surfaces of the specimens for electrical testing. The technology of obtaining the composite compositions was described in detail in Reference [34]. The general scheme of the technological process of the PP-F ceramic composite samples is presented in Figure $1 \mathrm{~b}$.

The designed compositions of the PMN-PT-ferrite (PP-F) with the general formula $0.9\left[(1-x)\right.$ PMN- $x$ PT] $-0.1\left(\mathrm{Ni}_{0.64} \mathrm{Zn}_{0.36} \mathrm{Fe}_{2} \mathrm{O}_{4}\right)$ with $x=0.25,0.28,0.31,0.34,0.37,0.40$, were identified as PP25-F, PP28-F, PP31-F, PP34-F, PP37-F, PP40-F, respectively.

The microstructure tests of the composite samples were performed using a JEOL (Tokyo, Japan) JSM-7100 TTL LV field emission scanning electron microscope equipped with an energy dispersive spectrometer (EDS) and a backscattered electron detector (BSE). The dielectric measurements (in a temperature range from $20{ }^{\circ} \mathrm{C}$ to $450{ }^{\circ} \mathrm{C}$ ) were performed using a capacity bridge of a QuadTech 1920 LCR meter (Quad/Tech, Inc., Maynard, MA, USA) for the cycle of heating (at frequencies of the measurement field from $1 \mathrm{kHz}$ to $100 \mathrm{kHz}$ ). The hysteresis $(P-E)$ loops were investigated with a Sawyer-Tower circuit and a Matsusada Inc. (Kusatsu, Japan) HEOPS-5B6 high voltage amplifier. The electromechanical measurements were carried out using an optical displacement meter (Philtec Inc., Annapolis, MD, USA, D63) and a HEOPS-5B6 high voltage amplifier. The data were stored on a computer disc using an A/D, D/A transducer card and the LabView computer program. The DC electrical conductivity was measured using a Keithley 6517B electrometer high-resistance meter (Cleveland, $\mathrm{OH}, \mathrm{USA}$ ) in a temperature range from $20^{\circ} \mathrm{C}$ to $480{ }^{\circ} \mathrm{C}$.

\section{Results and Discussion}

In previous work [35], the XRD measurements of the six compositions of (1-x)PMN- $x$ PT with $x=0.25,0.28,0.31,0.34,0.37,0.40$, as well as the ceramic composite PP-F obtained based on them, were presented. The PMN-PT has rhombohedral symmetry, tetragonal symmetry, and a mixture of 
these two phases (morphotropic area) that determine the electrophysical properties of the materials. The XRD (PANalytical, Phillips X'Pert Pro, Eindhoven, The Netherlands) tests of the composite PP-F samples additionally showed small peaks derived from the ferrite phase (cubic spinel lines). Moreover, the EDS tests (not presented here) confirmed the assumed chemical composition of PP-F and the presence of maxima from elements originating in PMN-PT, as well as elements originating in ferrite [35].

Figure 2 shows the microstructural SEM images of the fractured PMN-PT ceramic samples (PP) obtained using the sol-gel method. The PP samples with rhombohedral symmetry (Figure 2-PP25, PP28) have a fine-grained microstructure, with well-crystallized grains. On the other hand, in the PP samples with tetragonal symmetry (Figure 2-PP37, PP40), slightly larger grains are observed. In the PP samples from the morphotropic area both small and large grains are present (Figure 2-PP31, PP34).
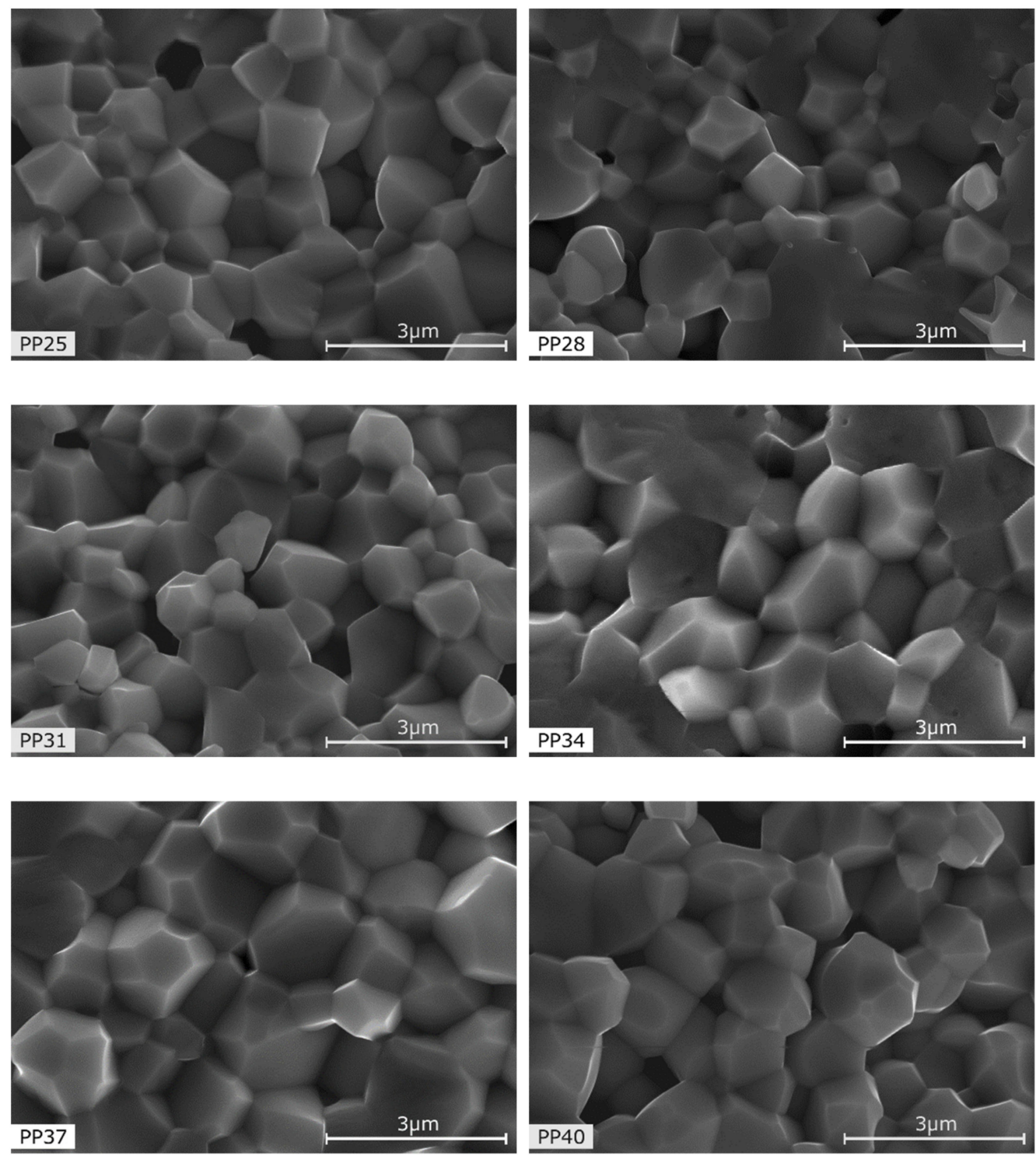

Figure 2. SEM microstructure of PP ceramics for: PP25 for $x=0.25$, PP28 for $x=0.28$, PP31 for $x=0.31$, PP34 for $x=0.34$, PP37 for $x=0.37$, PP40 for $x=0.40$.

Figure 3 shows microstructural SEM images of the PMN-PT-ferrite composite samples (PP-F). The images were taken in the standard SB mode (detection of the assembly of signals from the secondary and backscattered electron detectors-Figure $3 \mathrm{a}, \mathrm{c}, \mathrm{e}, \mathrm{g}, \mathrm{i}, \mathrm{k}$ ), as well as BSE mode (detection of backscattered electrons-Figure $3 b, d, f, h, j, l)$. In the BSE mode, the backscattered electrons are predominantly detected thanks to the filtering of low-energy secondary electrons. The observation 
of backscattered electrons allows the visualization of differences in the composition of the sample using different levels of contrast. Using a reduced signal level from the backscattered electron detector, one can observe an image of the composition of elements with a higher atomic number (bright area) and the topography of the elements with a lower atomic number (dark area), e.g., ferrite grains.
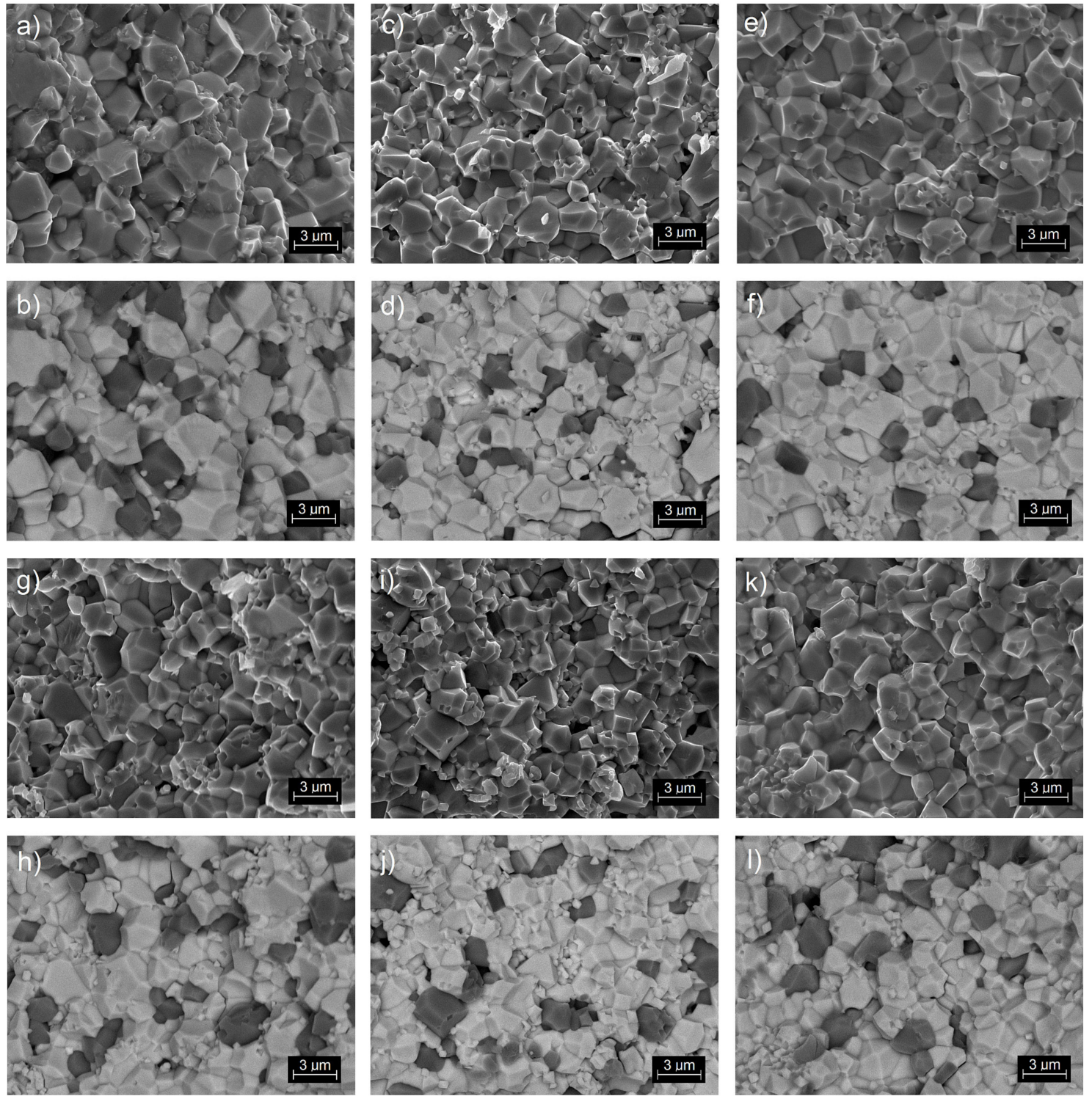

Figure 3. SEM microstructure of PP-F samples: (a,b) PP25-F, (c,d) PP28-F, (e,f) PP31-F, (g,h) PP34-F, (i,j) PP37-F, (k,1) PP40-F. The images were taken in the standard SB mode (detection of the assembly of signals from the secondary and backscattered electron detectors-Figure $3 \mathrm{a}, \mathrm{c}, \mathrm{e}, \mathrm{g}, \mathrm{i}, \mathrm{j}$ ) and BSE (detection of backscattered electrons-Figure $3 b, d, f, h, j, l)$.

The BSE images of the microstructure of fractures obtained for the PMN-PT-ferrite composites show the existence of a PMN-PT matrix (which is of higher atomic number, appearing white) and ferrite inclusions (dark grains with lower atomic number). The SEM tests confirmed that the ferrite grains are randomly distributed throughout the entire sample volume. Comparing the microstructures from Figures 2 and 3, one can see that in PP-F samples, the grains are larger and better crystallized. Just as in the PP samples, in the PP-F samples with compositions from the MPB area both small and large grains are visible. 
Previous magnetic measurements [35] confirmed that above room temperature, the obtained composite materials exhibit magnetic (ferrimagnetic) properties, with very slim magnetic hysteresis loops, and that such magnetic properties do not depend on the ferroelectric component of the composites.

Figure 4 compares the temperature dependence of dielectric permittivity for the PP ceramics and the PP-F composite samples obtained at various frequencies. In the case of the PP-F, the maximum dielectric permittivity occurs in a narrower range of temperatures. The phase transition does not depend on the frequency of the measuring field. Analysing $\varepsilon(T)$ dependencies above the ferroelectric-paraelectric phase transitions, one can observe the next maximum with a very broad and dispersive peak of dielectric permittivity for all investigated PP-F composite samples. One reason for this may be the presence of the magnetic component (ferrite) in the composite exhibiting phase transition in this area. In the same range of temperatures, a strong frequency dependency is observed (Figure 4) for the obtained compositions. These broad peaks shift towards higher temperatures with increasing frequency of the measurement field. This phenomenon may be associated with the imposition of a number of factors, for instance, as a result of relaxation processes as well as an increase in electrical conductivity in composite samples at high temperatures [36-40].

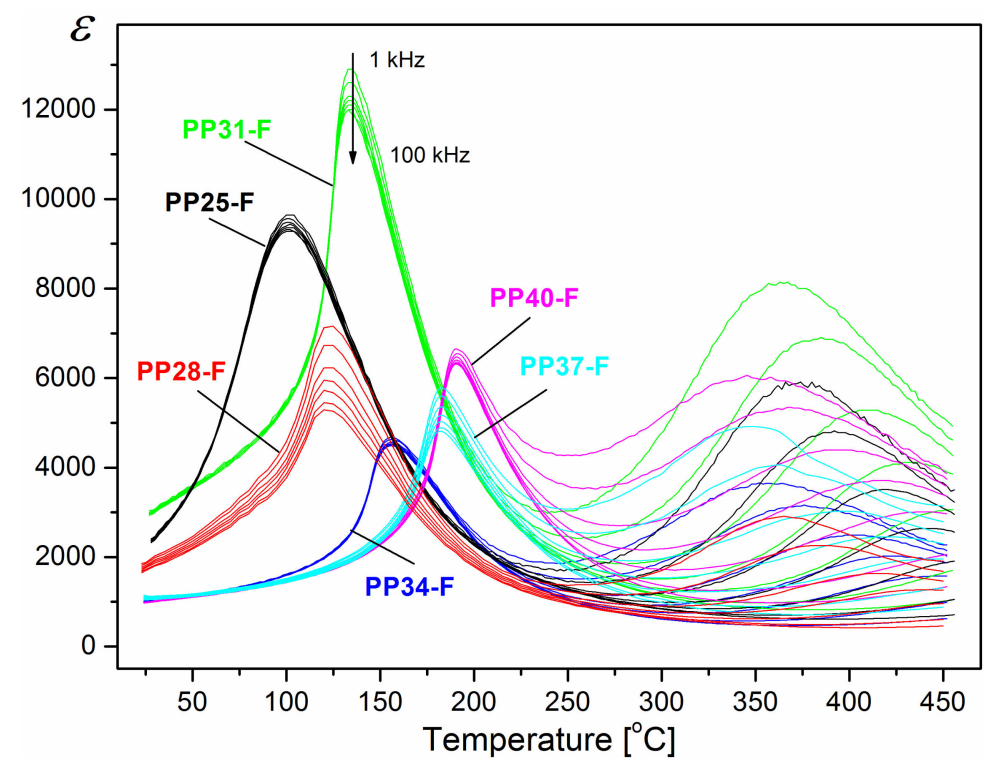

Figure 4. Temperature dependencies of dielectric permittivity $\varepsilon$ for the PP-F ceramic composites (heating cycle, frequency: $1 \mathrm{kHz}, 2 \mathrm{kHz}, 5 \mathrm{kHz}, 10 \mathrm{kHz}, 20 \mathrm{kHz}, 50 \mathrm{kHz}, 100 \mathrm{kHz}$ ).

For a clear comparison, the results of the dielectric investigations of samples are presented in Figure 5a (for PP samples) and Figure 5b (for PP-F composite samples) for $1 \mathrm{kHz}$ frequency. In the majority of investigated compositions of PP-F, the values of maximum dielectric permittivity are higher in comparison with the PP samples. It is also seen that for PP-F samples, the temperatures at which the maxima of dielectric permittivity take place $\left(T_{m}\right)$ are shifted towards lower temperatures in comparison with the PP samples (Figure 6, Tables 1 and 2). 

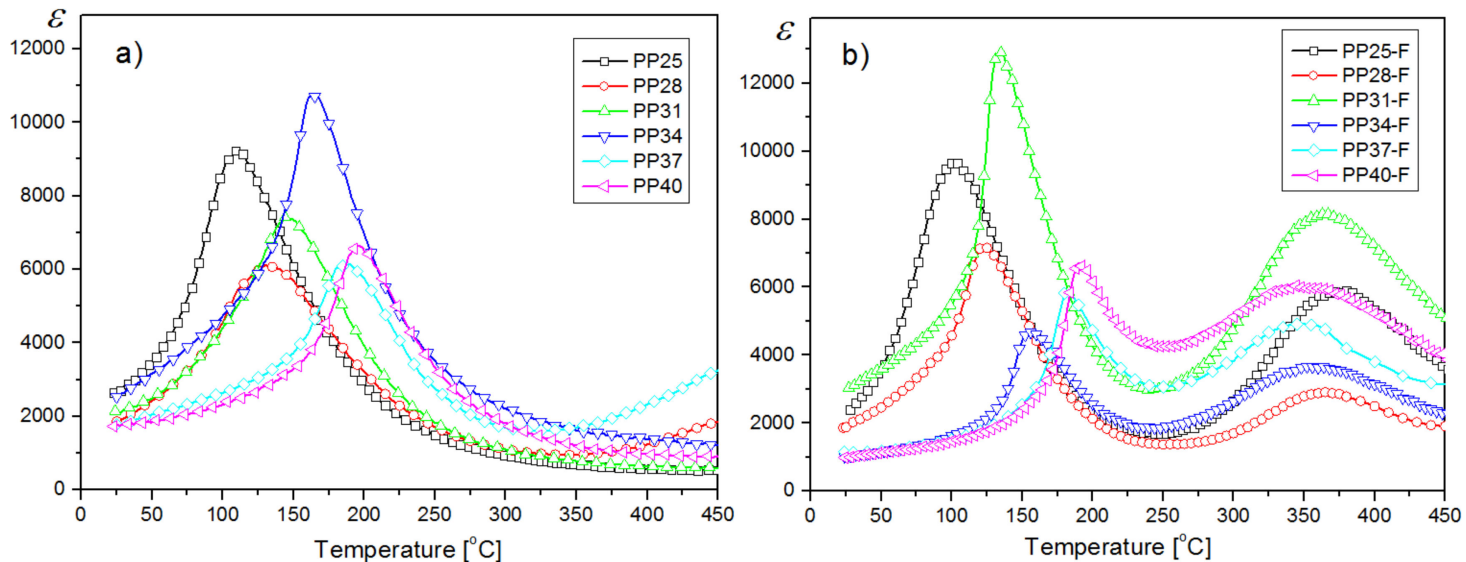

Figure 5. Temperature dependencies of dielectric permittivity for PP ceramics (a) and for PP-F ceramic composites (b) (heating cycle, frequency $1 \mathrm{kHz}$ ).

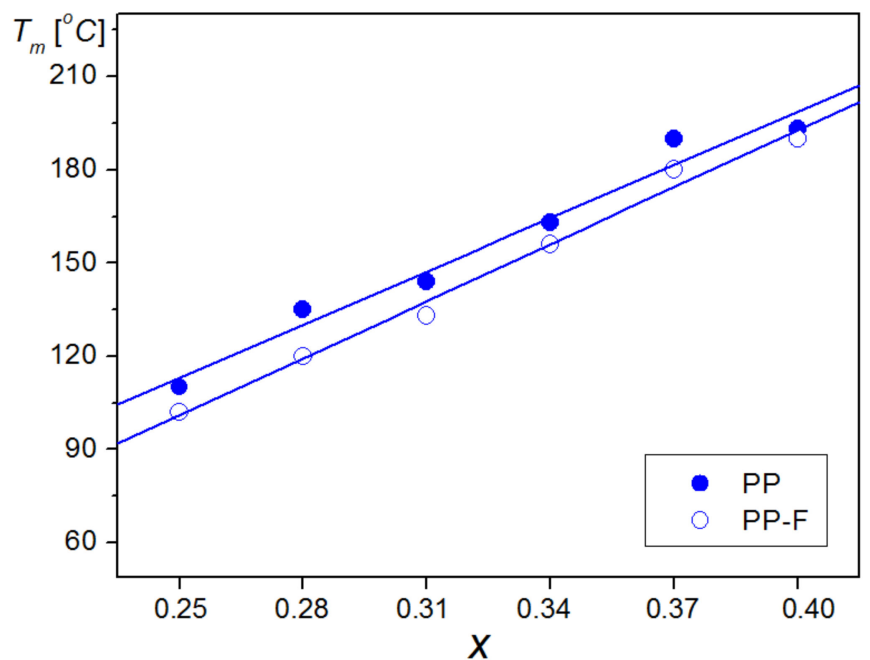

Figure 6. Dependencies of temperature of maximum dielectric permittivity $T_{m}(x)$ on $x$ (heating cycle, frequency $1 \mathrm{kHz}$ ).

Table 1. Electrophysical parameters of PMN-PT solid solutions.

\begin{tabular}{ccccccc}
\hline Parameter & PP25 & PP28 & PP31 & PP34 & PP37 & PP40 \\
\hline$\rho\left[\mathrm{g} / \mathrm{cm}^{3}\right]$ & 7.15 & 7.45 & 7.35 & 7.51 & 7.21 & 7.01 \\
$T_{m}\left[{ }^{\circ} \mathrm{C}\right]$ & 110 & 132 & 146 & 163 & 187 & 195 \\
$\varepsilon_{r}$ & 2620 & 1730 & 2080 & 2390 & 1830 & 1700 \\
$\varepsilon_{m}$ & 9170 & 6050 & 7350 & 10,760 & 6010 & 6620 \\
$\tan \delta$ at $T$ & 0.113 & 0.023 & 0.092 & 0.200 & 0.021 & 0.118 \\
$\tan \delta$ at $T_{m}$ & 0.108 & 0.023 & 0.062 & 0.225 & 0.030 & 0.101 \\
$P_{S}\left[\mu \mathrm{C} / \mathrm{cm}^{2}\right]$ & 22.30 & 24.86 & 25.70 & 27.30 & 25.70 & 20.16 \\
$P_{R}\left[\mu \mathrm{C} / \mathrm{cm}^{2}\right]$ & 19.31 & 21.00 & 22.46 & 20.90 & 22.26 & 18.22 \\
$E_{c}\left[\mathrm{kV} / \mathrm{mm}^{2}\right]$ & 0.82 & 0.67 & 0.79 & 0.96 & 1.04 & 1.32 \\
$E_{A c t}$ in I $[\mathrm{eV}]$ & 0.009 & 0.059 & 0.011 & 0.012 & 0.052 & 0.017 \\
$E_{A c t}$ in II $[\mathrm{eV}]$ & 1.412 & 1.729 & 0.996 & 1.069 & 1.619 & 0.936 \\
$H_{S}[\%]$ & 13.61 & 14.06 & 29.52 & 12.20 & 37.51 & - \\
$S_{r e s t}[\%]$ & 0.029 & 0.020 & 0.029 & 0.024 & 0.017 & - \\
$d_{33}[\mathrm{pC} / \mathrm{N}]$ & 613 & 946 & 956 & 687 & 1243 & -
\end{tabular}

$\rho$-density, $T_{m}$-temperature at maximum of dielectric permittivity, $\varepsilon_{r}, \varepsilon_{m}$ - dielectric permittivity at room temperature and $T_{m}$, respectively, $\tan \delta$-dielectric loss, $P_{S}, P_{R}$-spontaneous and remnant polarization, respectively, $E_{c}$ - coercive field, $E_{A c t}$-activation energy, $H_{S}$ - strain hysteresis coefficient, $S_{\text {rest }}$-residual strain, $d_{33}$-piezoelectric coefficient. 
Table 2. Electrophysical parameters of PP-F composite materials.

\begin{tabular}{ccccccc}
\hline Parameter & PP25-F & PP28-F & PP31-F & PP34-F & PP37-F & PP40-F \\
\hline$\rho\left[\mathrm{g} / \mathrm{cm}^{3}\right]$ & 7.20 & 7.41 & 7.39 & 7.13 & 7.19 & 7.02 \\
$T_{m}\left[{ }^{\circ} \mathrm{C}\right]$ & 102 & 123 & 134 & 157 & 182 & 191 \\
$\varepsilon_{r}$ & 1860 & 1750 & 2900 & 1090 & 1225 & 980 \\
$\varepsilon_{m}$ & 9660 & 7180 & 12,910 & 4750 & 9910 & 6630 \\
$\tan \delta$ at $T_{r}$ & 0.007 & 0.040 & 0.009 & 0.005 & 0.008 & 0.007 \\
$\tan \delta$ at $T_{m}$ & 0.026 & 0.137 & 0.059 & 0.041 & 0.063 & 0.061 \\
$P_{S}\left[\mu \mathrm{C} / \mathrm{cm}^{2}\right]$ & 13.21 & 12.02 & 16.57 & 13.90 & 7.58 & 9.29 \\
$P_{R}\left[\mu \mathrm{C} / \mathrm{cm}^{2}\right]$ & 9.26 & 8.30 & 11.32 & 10.23 & 4.45 & 6.46 \\
$E_{c}\left[\mathrm{kV} / \mathrm{mm}^{2}\right]$ & 0.46 & 0.58 & 0.62 & 0.74 & 0.79 & 0.97 \\
$E_{\text {Act }}$ in I $[\mathrm{eV}]$ & 0.377 & 0.346 & 0.623 & 0.610 & 0.062 & 0.438 \\
$E_{\text {Act }}$ in II $[\mathrm{eV}]$ & 0.978 & 1.147 & 1.287 & 1.130 & 1.483 & 1.109 \\
$H_{S}[\%]$ & 15.45 & 18.28 & 7.32 & 63.30 & 19.16 & 38.51 \\
$S_{\text {rest }}[\%]$ & 0.012 & 0.014 & 0.011 & 0.010 & 0.001 & 0.004 \\
$d_{33}[\mathrm{pC} / \mathrm{N}]$ & 553 & 1070 & 446 & 133 & 70 & 71 \\
\hline
\end{tabular}

The measurement of $P(E)$ electric hysteresis loops for PMN-PT solid solutions and PP-F composite materials showed that increasing the amount of PT in PMN-PT causes an increase in the value of the coercive field in the PP-F composite samples (Figure 7). The composite samples with tetragonal structures exhibit lower values of spontaneous polarization $\left(P_{S}\right)$ and remnant polarization $\left(P_{R}\right)$, while the samples from the MPB morphotropy area are characterized by indirect values of coercive field $\left(E_{c}\right), P_{R}$, and $P_{S}$. The obtained results confirm ferroelectric and weak ferromagnetic properties at room temperature for the obtained ceramic composite samples. The $P(E)$ electric hysteresis loops at room temperature and frequency of $1 \mathrm{~Hz}$ for the obtained materials were presented in Reference [26].

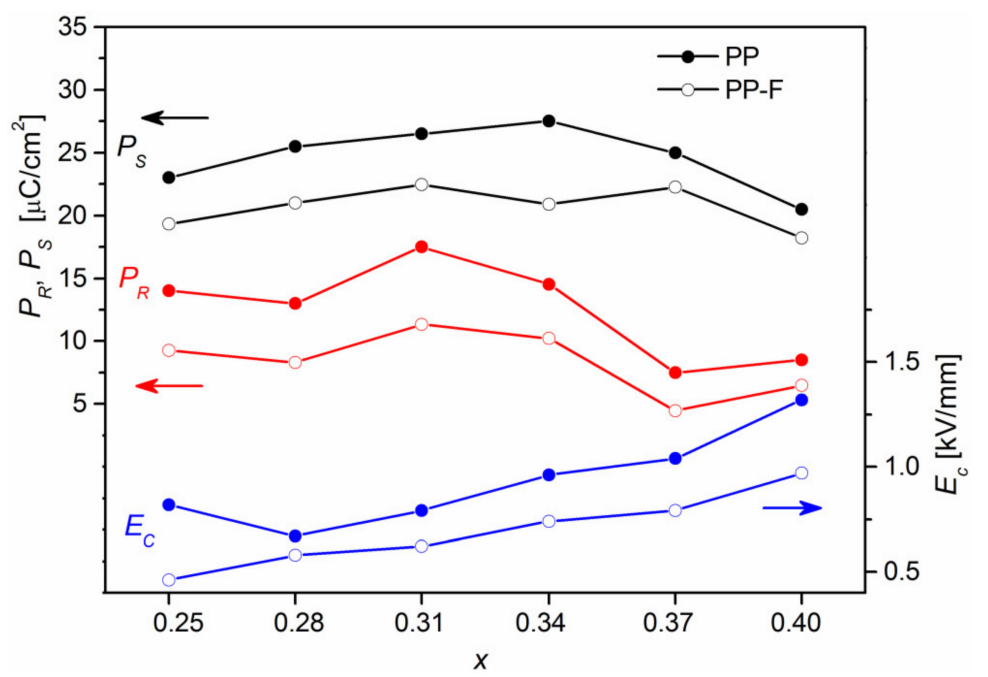

Figure 7. Dependence of remnant polarization $P_{R}$, spontaneous polarization $P_{S}$, and coercive field $E_{\mathcal{C}}$ of the $(1-x) \mathrm{PMN}-x \mathrm{PT}$ with $x=0.25,0.28,0.31,0.34,0.37,0.40$.

The electromechanical properties of the PMN-PT solid solutions and the ceramic PP-F composites are presented in Figure 8a,b, respectively. The measurements show that the strains in the samples with ferrite are lower. This could be expected, since part of the volume is filled with material that does not exhibit piezoelectric/electrostrictive properties. The $S-E$ electromechanic loops have a specific shape ("butterfly wings"). For the majority of the investigated samples, in some range of $E$, a nearly linear relation $S(E)$ is observed, which indicates the piezoelectric nature of the strain. The values of $S_{\text {rest }}$ residual strain and $H_{S}$ strain hysteresis coefficient for PMN-PT ceramic samples demonstrate higher 
values compared with the composite PP-F samples (Tables 1 and 2). The strain hysteresis coefficient $H_{S}$ was calculated using the following formula [41]:

$$
H_{S}=\frac{\Delta S_{\text {half }} \times 100 \%}{S_{\max }}
$$

where $\Delta S_{\text {half }}$ is the hysteresis of strains (the difference between maximum and minimum strain value for the half of the maximum electric field) and $S_{\max }$ is the strain value for the maximum of the applied electric field.
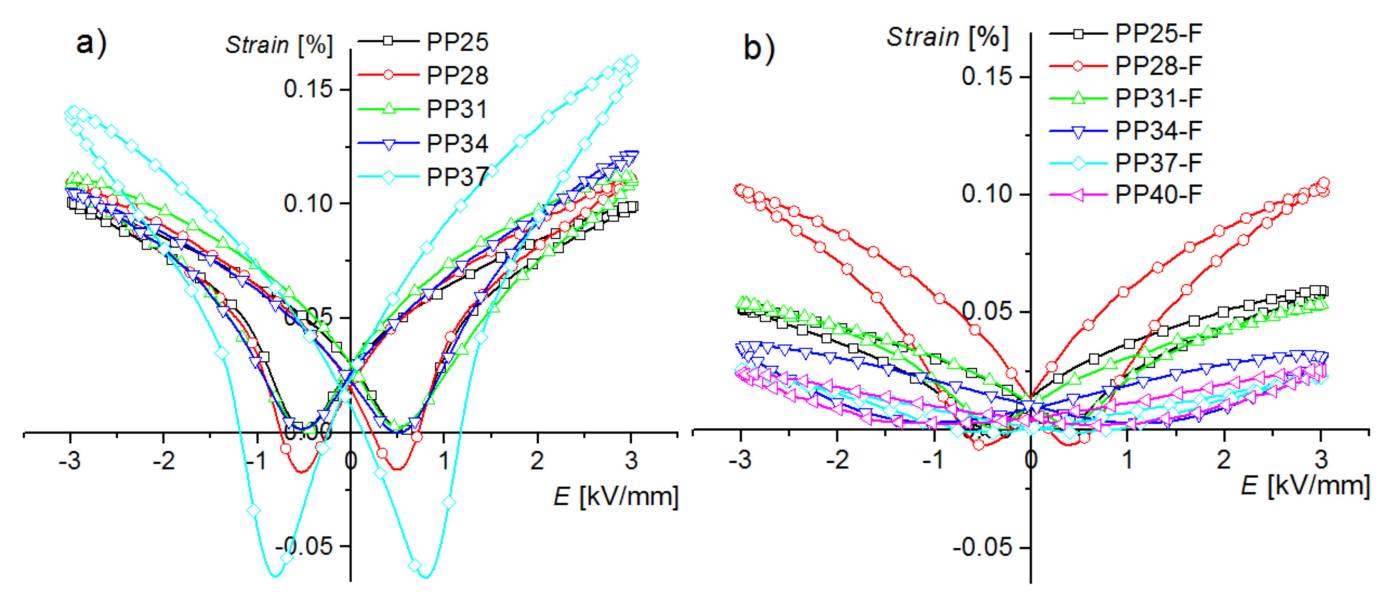

Figure 8. Bipolar strain-electric field loops $(S-E)$ for (a) PP ceramics and (b) PP-F composite materials.

The piezoelectric coefficient of the obtained ceramic samples measured using a frequency of $0.1 \mathrm{~Hz}$ and calculated as a maximal value of the derivative $\frac{\partial S}{\partial E}$ is presented in Figure 9, as well as in Tables 1 and 2, for the PP samples and the PP-F composites, respectively. In the great majority of compounds, much higher values of the piezoelectric properties are observed for the PMN-PT solid solutions. The PMN-PT single crystals with PT content from $27 \%$ to about $33 \%$ have superior piezoelectric properties in relation to the traditional PZT ceramics [42-44]. For the PMN-28PT, the ceramics deformation is slightly smaller than in classic PZT piezoceramics (e.g., PZT-5H ceramics), but still has a high strain value.

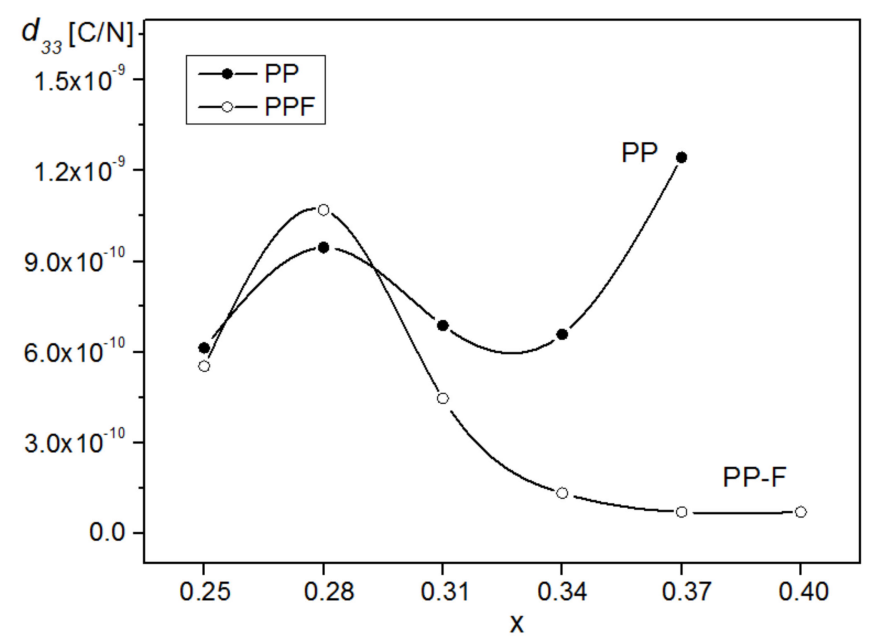

Figure 9. Dependencies of the piezoelectric coefficient $d_{33}$ of the obtained ceramic samples (frequency $0.1 \mathrm{~Hz}$ ).

For the obtained ceramic samples of PMN-PT, the highest values of the piezoelectric coefficient $\left(d_{33}\right)$ are exhibited by the samples with $x=0.37$ (tetragonal phase) and $x=0.28$ (rhombohedral 
phase). Introduction to PMN-PT compounds of the ferrite compound significantly reduces the value of $d_{33}$ (except for the PP28-F composition). The highest value of $d_{33}$ is exhibited by the composition with $x=0.28$, and the successive values of $d_{33}$ decrease with increasing $x$ in PMN-PT in PP-F composite samples.

The results of the investigations of DC electrical conductivity are presented in Figure 10a (for PP) and Figure 10b (for PP-F). Quite significant differences in dependency $\ln \sigma_{D C}(1000 / T)$ (consisting of an increase in electrical conductivity) between the PP and PP-F samples are observed for 1000/T, in the temperature range $330-500 \mathrm{~K}\left(57-227^{\circ} \mathrm{C}\right)$, which denotes significant differences in electrical conductivity near the phase-transition temperature. These differences are more pronounced for the samples with less content of $\mathrm{PbTiO}_{3}$. This can be important information in the development of technologies of composite materials.
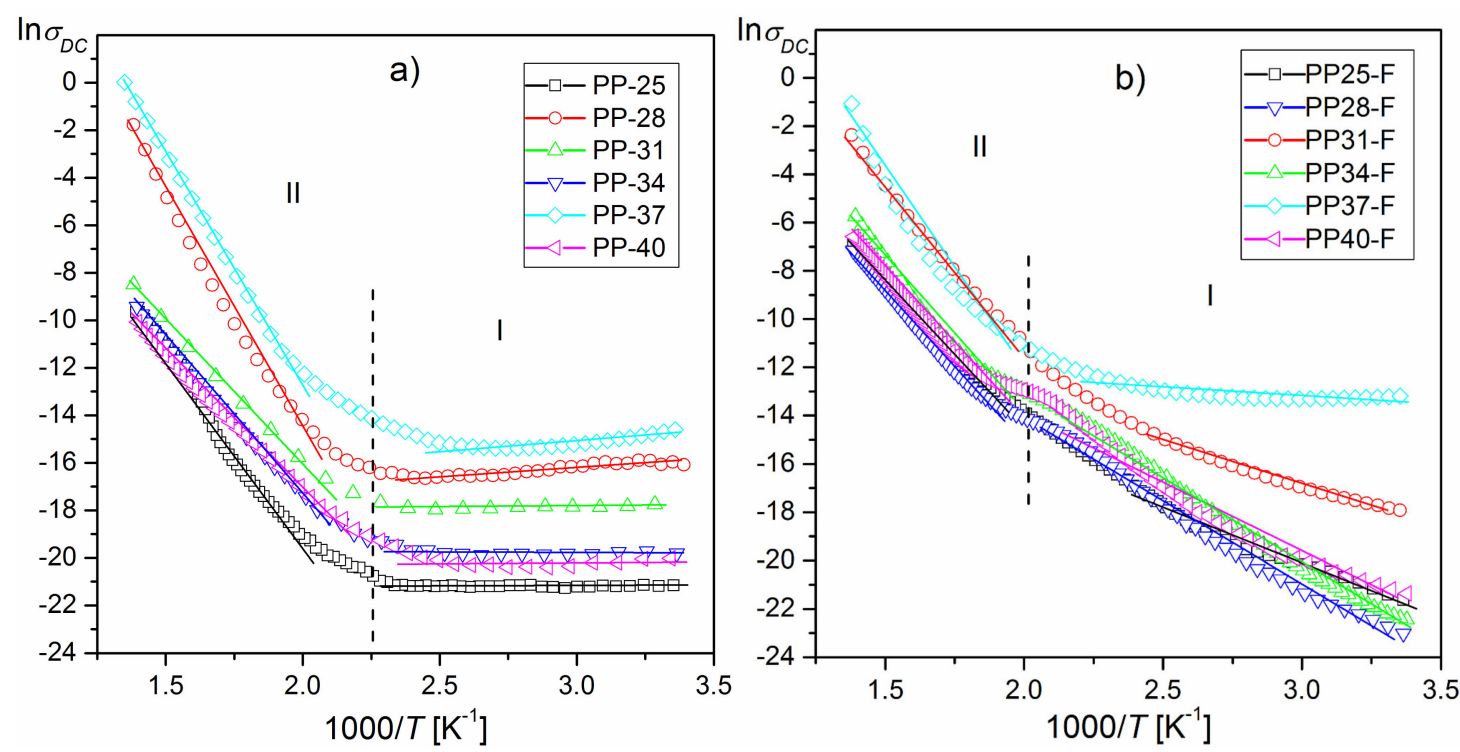

Figure 10. Influence of $x(\mathrm{PT})$ in PP ceramics (a) and PP-F composite samples (b) on $\ln \sigma_{D C}(1000 / T)$ dependencies.

The graphs $\ln \sigma_{D C}(1000 / T)$ show changes in the slope of the curves (two regions of the graph) with different values of activation energy. Activation energy was calculated from the slope of the $\ln \sigma_{\mathrm{DC}}(1000 / T)$ plot according to the Arrhenius law [45]:

$$
\sigma_{D C}=\sigma_{0} e^{-\frac{E_{A c t}}{k_{B} T}}
$$

where $\sigma_{0}$ is the pre-exponential factor, $k_{B}$ is the Boltzmann constant, $E_{A c t}$ is the activation energy, and $T$ is the absolute temperature. Values of the activation energy calculated according to Formula (2) in two temperature areas are given in Tables 1 and 2.

\section{Conclusions}

New ferroelectromagnetic ceramic PP-F composites based on PMN-PT and ferrite powders, as well as PMN-PT ceramic samples, were successfully obtained and compared. The PP samples with rhombohedral symmetry have a fine-grained microstructure, with well-crystallized grains, while the PP samples with tetragonal symmetry have rather larger grains. The microstructure of the PP samples from the MPB morphotropic area shows both small and large grains. The microstructures of the PP-F composite samples characterised by larger grains are better crystallized.

Previous magnetic measurements confirmed that above room temperature, the obtained composite materials show magnetic (ferrimagnetic) and ferroelectric properties, and that the magnetic properties 
do not dependent on the ferroelectric component of the composites. Addition of ferrite to the PMN-PT compound leads to a decrease in the values of remnant and spontaneous polarization, and coercive field.

The dielectric measurements show that in all PP-F samples, an additional maximum of dielectric permittivity at temperatures about $350-370{ }^{\circ} \mathrm{C}$ is observed, which does not exhibit the dispersion of dielectric permittivity in the frequency range of $10^{3}-10^{5} \mathrm{~Hz}$. The dielectric measurements indicated that the magnetic subsystem influences the dielectric properties (value of dielectric permittivity and dielectric loss).

The designed and obtained ceramic PP-F composite with good dielectric, magnetic, and piezoelectric properties confirmed the adequately conducted ceramic technology (i.e., synthesis by sol-gel method of the PMN-PT powders, selection of the sintering conditions, appropriate proportion of ferrite and ferroelectric powder, etc.), which allows the production of ferro-electro-magnetic materials with very interesting properties for specific applications in microelectronics and micromechatronics. These types of materials are very suitable for use in various types of piezoelectric transducers, sensors, servomotors, phase modulators, magnetoelectric transducers, piezoelectric-magnetostrictive accelerometers, etc.

Author Contributions: D.B. (Dariusz Bochenek)—main author and originator of the paper, participation in the technology for obtaining ceramic and composite samples, performance of the dielectric measurements, SEM tests, and interpretation of most measurements in this work. P.N.- participation in the technology for obtaining ceramic composite samples, performance of most measurements in the paper. R.S.-planning experimental research and interpreting results. D.B. (Dagmara Brzezińska)—participation in the technology for obtaining ceramic samples.

Funding: This research received no external funding.

Conflicts of Interest: The authors declare no conflicts of interest.

\section{References}

1. Khomskii, D. Classifying multiferroics: Mechanisms and effects. Physics 2009, 2, 20. [CrossRef]

2. Schmid, H. Some symmetry aspects of ferroics and single phase multiferroics. J. Phys. Condens. Matter 2008, 20, 434201. [CrossRef]

3. Wu, P.P.; Ma, X.Q.; Zhang, J.X.; Chen, L.Q. Phase-field model of multiferroic composites: Domain structures of ferroelectric particles embedded in a ferromagnetic matrix. Philos. Mag. 2010, 90, 125-140. [CrossRef]

4. Fiebig, M.; Lottermoser, T.; Meier, D.; Trassin, M. The evolution of multiferroics. Nat. Rev. 2016, 1, 1-14.

5. Scott, J.F. Applications of magnetoelectrics. J. Mater. Chem. 2012, 22, 4567-4574. [CrossRef]

6. Wang, K.F.; Liu, J.-M.; Ren, Z.F. Multiferroicity: the coupling between magnetic and polarization orders. Adv. Phys. 2009, 58, 321-448. [CrossRef]

7. Uchino, K.; Giniewicz, J.R. Micromechatronics; Marcel Dekker: New York, NY, USA, 2003.

8. Sonoda, K.; Juuti, J.; Moriya, Y.; Jantunen, H. Modification of the dielectric properties of 0-3 ceramic-polymer composites by introducing surface active agents onto the ceramic filler surface. Compos. Struct. 2010, 92, 1052-1058. [CrossRef]

9. Bichurin, M.I.; Nan, C.-W.; Bichurin, M.; Dong, S.; Viehland, D.; Srinivasan, G. Multiferroic magnetoelectric composites: Historical perspective, status, and future directions. J. Appl. Phys. 2008, 103, 31101.

10. Kulawik, J.; Szwagierczak, D.; Guzdek, P. Multiferroic Cobalt Ferrite-Lead Iron Tungstate Composites. Acta Phys. Pol. A 2012, 121, 122-124. [CrossRef]

11. Zhang, H.; Mak, C.-L. Impedance spectroscopic characterization of fine-grained magnetoelectric $\mathrm{Pb}\left(\mathrm{Zr}_{0.53} \mathrm{Ti}_{0.47}\right) \mathrm{O}_{3}-\left(\mathrm{Ni}_{0.5} \mathrm{Zn}_{0.5}\right) \mathrm{Fe}_{2} \mathrm{O}_{4}$ ceramic composites. J. Alloy. Compd. 2012, 513, 165-171. [CrossRef]

12. Hrib, L.; Caltun, O. Effects of the chemical composition of the magnetostrictive phase on the dielectric and magnetoelectric properties of cobalt ferrite-barium titanate composites. J. Alloy. Compd. 2011, 509, 6644-6648. [CrossRef]

13. Bochenek, D.; Niemiec, P.; Zachariasz, R.; Chrobak, A.; Ziółkowski, G. Ferroelectric- ferromagnetic composites based on PZT type powder and ferrite powder. Arch. Metall. Mater. 2013, 58, 1013-1017. [CrossRef]

14. Zhang, S.; Luo, W.; Wang, L.; Wang, D.; Ma, Y. Simultaneously improved magnetization and polarization in $\mathrm{BiFeO}_{3}$ based multiferroic composites. J. Appl. Phys. 2010, 107, 54110. [CrossRef] 
15. Bochenek, D.; Niemiec, P.; Chrobak, A.; Ziółkowski, G.; Błachowski, A. Magnetic and electric properties of the lead free ceramic composite based on the BFN and ferrite powders. Mater. Charact. 2014, 87, 36-44. [CrossRef]

16. Pradhan, D.K.; Chowdhury, R.N.P.; Nath, T.K. Magnetoelectric properties of $\mathrm{PbZr}_{0.53} \mathrm{Ti}_{0.47} \mathrm{O}_{3}-\mathrm{Ni}_{0.65} \mathrm{Zn}_{0.35} \mathrm{Fe}_{2} \mathrm{O}_{4}$ multiferroic nanocomposites. Appl. Nanosci. 2012, 2, 261-273. [CrossRef]

17. Thankachan, R.M.; Raneesh, B.; Mayeen, A.; Karthika, S.; Vivek, S.; Nair, S.S.; Thomas, S.; Kalarikkal, N. Room temperature magnetoelectric coupling effect in $\mathrm{CuFe}_{2} \mathrm{O}_{4}-\mathrm{BaTiO}_{3}$ core-shell and nanocomposites. J. Alloy. Compd. 2018, 731, 288-296. [CrossRef]

18. Bochenek, D.; Zachariasz, R. PFN ceramics synthesized by a two-stage method. Arch. Metall. Mater. 2009, 54, 903-910.

19. Wei, J.; Xue, D.; Wu, C.; Li, Z. Enhanced ferromagnetic properties of multiferroic $\mathrm{Bi}_{1-x} \mathrm{Sr}_{\mathrm{x}} \mathrm{Mn}_{0.2} \mathrm{Fe}_{0.8} \mathrm{O}_{3}$ synthesized by sol-gel process. J. Alloy. Compd. 2008, 453, 20-23. [CrossRef]

20. Bochenek, $\mathrm{D}$. Magnetic and ferroelectric properties of $\mathrm{PbFe}_{1 / 2} \mathrm{Nb}_{1 / 2} \mathrm{O}_{3}$ synthesized by a solution precipitation method. J. Alloy. Compd. 2010, 504, 508-513. [CrossRef]

21. Bochenek, D.; Niemiec, P.; Adamczyk, M.; Szafraniak-Wiza, I. Physical properties of lead-free $\mathrm{BaFe}_{1 / 2} \mathrm{Nb}_{1 / 2} \mathrm{O}_{3}$ ceramics obtained from mechanochemically synthesized powders. J. Mater. Sci. 2018, 53, 1-12. [CrossRef]

22. Sofia, D.; Granese, M.; Barletta, D.; Poletto, M. Laser Sintering of Unimodal Distributed Glass Powders of Different Size. Procedia Eng. 2015, 102, 749-758. [CrossRef]

23. Sofia, D.; Barletta, D.; Poletto, M. Laser sintering process of ceramic powders: The effect of particle size on the mechanical properties of sintered layers. Addit. Manuf. 2018, 23, 215-224. [CrossRef]

24. Su, X.; Fu, F.; Yan, Y.; Zheng, G.; Liang, T.; Zhang, Q.; Cheng, X.; Yang, D.; Chi, H.; Tang, X.; et al. Self-propagating high-temperaa ture synthesis for compound thermoelectrics and new criterion for combustion processing. Nat. Commun. 2014, 5, 4908. [CrossRef] [PubMed]

25. Lackner, M. Combustion Synthesis: Novel Routes to Novel Materials; Bentham Science: Sharjah, UAE, 2010.

26. Sheikh, A.D.; Mathe, V. Dielectric, ferroelectric, magnetic and magnetoelectric properties of PMN-PT based ME composites. J. Phys. Chem. Solids 2011, 72, 1423-1429. [CrossRef]

27. Yu, S.; Huang, H.; Zhou, L.; Ye, Y.; Ke, S. Structure and properties of PMN-PT/NZFO laminates and composites. Ceram. Int. 2008, 34, 701-704. [CrossRef]

28. Amorín, H.; Holc, J.; Algueró, M.; Ricote, J.; Chateigner, D.; Kosec, M. Combined Structural and Quantitative Texture Analysis of Morphotropic Phase Boundary $\mathrm{Pb}\left(\mathrm{Mg}_{1 / 3} \mathrm{Nb}_{2 / 3}\right) \mathrm{O}_{3}-\mathrm{PbTiO}_{3}$ Ceramics. J. Am. Ceram. Soc. 2012, 95, 2965-2971. [CrossRef]

29. Noheda, B.; Cox, D.E.; Shirane, G.; Gao, J.; Ye, Z.-G. Phase diagram of the ferroelectric relaxor $(1-\mathrm{x}) \mathrm{Pb}\left(\mathrm{Mg}_{1 / 3} \mathrm{Nb}_{2 / 3}\right) \mathrm{O}_{3}-(\mathrm{x}) \mathrm{PbTiO}_{3}$. Phys. Rev. B.

30. Shrout, T.R.; Chang, Z.P.; Kim, N.; Markgraf, S. Dielectric behavior of single crystals near the $(1-\mathrm{x}) \mathrm{Pb}\left(\mathrm{Mg}_{1 / 3} \mathrm{Nb}_{2 / 3}\right) \mathrm{O}_{3}-(\mathrm{x}) \mathrm{PbTiO}_{3}$ morphotropic phase boundary. Ferroelectr. Lett. 1990, 12, 63-69. [CrossRef]

31. Skulski, R.; Wawrzała, P.; Ćwikiel, K.; Bochenek, D. Dielectric and Electromechanical Behaviors of PMN-PT Ceramic Samples. J. Intell. Mater. Syst. Struct. 2007, 18, 1049-1056. [CrossRef]

32. Jiwei, Z.; Bo, S.; Liangying, Z.; Xi, Y. Preparation and dielectric properties by sol-gel derived PMN-PT powder and ceramic. Mater. Chem. Phys. 2000, 64,1-4. [CrossRef]

33. Reddy, M.P.; Madhuri, W.; Ramamanohar-Reddy, N.; Siva-Kumar, K.V.; Murthy, V.R.K.; Ramakrishna-Reddy, R. Magnetic properties of Ni-Zn ferrites prepared by microwave sintering method. J. Electroceram. 2012, 28, 1-9. [CrossRef]

34. Bochenek, D.; Niemiec, P.; Skulski, R.; Chrobak, A.; Wawrzała, P. Ferroelectric and magnetic properties of the PMN-PT-nickel zinc ferrite multiferroic ceramic composite materials. Mater. Chem. Phys. 2015, 157, 116-123. [CrossRef]

35. Skulski, R.; Bochenek, D.; Niemiec, P.; Brzezińska, D.; Chrobak, A. Technology and main properties of PMN-PT-ferrite multiferroic ceramic composite materials. Adaptive, Active and Multifunctional Smart Materials Systems. In Advances in Science and Technology; Trans Tech Publications: Zürich, Switzerland, 2017; Volume 98, pp. 3-8.

36. Li, M.-D.; Tang, X.-G.; Zeng, S.-M.; Jiang, Y.-P.; Liu, Q.-X.; Zhang, T.-F.; Li, W.-H. An oxygen defect-related dielectric relaxation behaviors of lead-free $\mathrm{Ba}\left(\mathrm{Hf}_{\mathrm{x}} \mathrm{Ti}_{1-\mathrm{x}}\right) \mathrm{O}_{3}$ ferroelectric ceramics. J. Phys. D Appl. Phys. 2018, 51, 485301. [CrossRef] 
37. Li, X.; Fan, X.; Xi, Z.; Liu, P.; Long, W.; Fang, P.; Guo, F.; Nan, R. Dielectric Relaxor and Conductivity Mechanism in Fe-Substituted PMN-32PT Ferroelectric Crystal. Crystals 2019, 9, 241. [CrossRef]

38. Zhang, T.F.; Tang, X.G.; Ge, P.Z.; Liu, Q.X.; Jiang, Y.P. Orientation related electrocaloric effect and dielectric phase transitions of relaxor PMN-PT single crystals. Ceram. Int. 2017, 43, 16300-16305. [CrossRef]

39. Li, X.J.; Jing, Q.; Xi, Z.Z.; Liu, P.; Long, W.; Fang, P.Y. Dielectric relaxation and electrical conduction in $\left(\mathrm{Bi}_{\mathrm{x}} \mathrm{Na}_{1-\mathrm{x}}\right)_{0.94} \mathrm{Ba}_{0.06} \mathrm{TiO}_{3}$ ceramics. J. Am. Ceram. Soc. 2018, 101, 789-799. [CrossRef]

40. Zhang, T.F.; Tang, X.G.; Liu, Q.X.; Jiang, Y.P.; Huang, X.X.; Zhou, Q.F. Energy-storage properties and high-temperature dielectric relaxation behaviors of relaxor ferroelectric $\mathrm{Pb}\left(\mathrm{Mg}_{1 / 3} \mathrm{Nb}_{2 / 3}\right) \mathrm{O}_{3}-\mathrm{PbTiO}_{3}$ ceramics. J. Phys. D Appl. Phys. 2016, 49, 9.

41. Bochenek, D.; Wawrzała, $\mathrm{P} . \mathrm{PbFe}_{1 / 2} \mathrm{Nb}_{1 / 2} \mathrm{O}_{3}$ ceramics as a base material for electromechanical transducers. Arch. Acoust. 2006, 31, 513-519.

42. Park, S.E.; Shrout, T.R. Ultrahigh strain and piezoelectric behavior in relaxor based ferroelectric single crystals. J. Appl. Phys. 1997, 82, 1804-1811. [CrossRef]

43. Guo, Y.; Luo, H.; Zhou, X.; Pan, X.; Yin, Z. Ultra-high piezoelectric response in $<110>$-oriented polydomain $\mathrm{Pb}\left(\mathrm{Mg}_{1 / 3} \mathrm{Nb}_{2 / 3}\right) \mathrm{O}_{3}-\mathrm{PbTiO}_{3}$ single crystals. Appl. Phys. A Mater. 2003, 77, 707-709. [CrossRef]

44. Zuo, R.; Granzow, T.; Lupescu, D.C.; Rodel, J. PMN-PT Ceramics Prepared by spark plasma sintering. J. Am. Ceram. Soc. 2007, 90, 1101-1106. [CrossRef]

45. Raymond, O.; Font, R.; Suárez-Almodovar, N.; Portelles, J.; Siqueiros, J.M. Frequency-temperature response of ferroelectromagnetic $\mathrm{PbFe}_{1 / 2} \mathrm{Nb}_{1 / 2} \mathrm{O}_{3}$ ceramics obtained by different precursors. Part I. Structural and thermo-electrical characterization. J. Appl. Phys. 2005, 97, 084107. [CrossRef]

(C) 2019 by the authors. Licensee MDPI, Basel, Switzerland. This article is an open access article distributed under the terms and conditions of the Creative Commons Attribution (CC BY) license (http://creativecommons.org/licenses/by/4.0/). 